\title{
Sensitive Detection of Thirteen Bacterial Vaginosis-Associated Agents Using Multiplex Polymerase Chain Reaction
}

\author{
Natália Malaguti, ${ }^{1}$ Larissa Danielle Bahls, ${ }^{1}$ Nelson Shozo Uchimura, \\ Fabrícia Gimenes, ${ }^{1}$ and Marcia Edilaine Lopes Consolaro ${ }^{1}$ \\ ${ }^{1}$ Clinical Cytology and STD Laboratory, Department of Clinical Analysis and Biomedicine, State University of Maringá, \\ 87020900 Maringá, PR, Brazil \\ ${ }^{2}$ Department of Medicine, State University of Maringá, 87020900 Maringá, PR, Brazil
}

Correspondence should be addressed to Marcia Edilaine Lopes Consolaro; melconsolaro@uem.br

Received 17 February 2015; Accepted 28 April 2015

Academic Editor: György Schneider

Copyright (C) 2015 Natália Malaguti et al. This is an open access article distributed under the Creative Commons Attribution License, which permits unrestricted use, distribution, and reproduction in any medium, provided the original work is properly cited.

\begin{abstract}
Bacterial vaginosis (BV) is characterized by a polymicrobial proliferation of anaerobic bacteria and depletion of lactobacilli, which are components of natural vaginal microbiota. Currently, there are limited conventional methods for BV diagnosis, and these methods are time-consuming, expensive, and rarely allow for the detection of more than one agent simultaneously. Therefore, we conceived and validated a multiplex polymerase chain reaction (M-PCR) assay for the simultaneous screening of thirteen bacterial vaginosis-associated agents (BV-AAs) related to symptomatic BV: Gardnerella vaginalis, Mobiluncus curtisii, Mobiluncus mulieris, Bacteroides fragilis, Mycoplasma hominis, Atopobium vaginae, Ureaplasma urealyticum, Megasphaera type I, Clostridia-like bacteria vaginosis-associated bacteria (BVABs) 1,2, and 3, Sneathia sanguinegens, and Mycoplasma genitalium. The overall validation parameters of M-PCR compared to single PCR (sPCR) were extremely high, including agreement of $99.1 \%$ and sensitivity, specificity, and positive predictive values of $100.0 \%$, negative predictive value of $97.0 \%$, accuracy of $99.3 \%$, and agreement with Nugent results of $100.0 \%$. The prevalence of BV-AAs was very high (72.6\%), and simultaneous agents were detected in $53.0 \%$, which demonstrates the effectiveness of the M-PCR assay. Therefore, the M-PCR assay has great potential to impact BV diagnostic methods in vaginal samples and diminish associated complications in the near future.
\end{abstract}

\section{Introduction}

Bacterial vaginosis (BV) is the most prevalent lower genital tract infection in women of reproductive age worldwide [1]. Women with BV typically report symptoms that include a thin vaginal discharge and a fishy malodor [2]. However, a substantial portion of affected women is asymptomatic [3]. The etiology of BV is not completely understood. No single etiological agent is the known cause of $\mathrm{BV}$, and the syndrome is considered an ecological disorder of the vaginal microbiota. $\mathrm{BV}$ is characterized by a reduction of lactic acid-producing bacteria (mainly Lactobacillus spp.) and an increase in the number and diversity of facultative and strictly anaerobic bacteria [4-6]. BV is an independent risk factor for adverse outcomes, including pelvic inflammatory disease (PID) $[7,8]$ and subsequent infertility [9], increased risk of preterm labor and delivery $[9,10]$, amniotic fluid infections [11], chorioamnionitis [12], low birth weight [13], endometritis [14], cervicitis [15], and an increased risk of acquiring sexually transmitted infections (STIs) and HIV $[5,16]$. Therefore, the diagnosis of BV is essential, especially in pregnant females, as early as possible to prevent complications [17]. The precise pathophysiology and epidemiology of BV and the optimal medical management of the condition are far from clear. Much of this lack of understanding is a direct result of the difficulty in establishing a diagnostic standard for this syndrome [18].

$\mathrm{BV}$ is often diagnosed clinically based on the criteria described by Amsel et al. [19], wherein three of the following four signs must be evident: vaginal fluid $\mathrm{pH}$ greater than 4.5; homogeneous vaginal discharge on examination; detection of a fishy odor upon addition of $10 \%$ potassium hydroxide to vaginal fluid; and the presence of significant clue cells (>20\%). 
Another method that is widely used for BV diagnosis is based on grading or scoring the microbiota in Gram-stained smears of vaginal fluid (Nugent scoring) [20]. BV diagnosis in research and laboratory settings depends on traditional methods, such as culture and Gram-staining vaginal smears $[5,21,22]$. Conventional microbiological approaches have only limited utility in evaluating patients for BV. The hallmark of the condition is a complex perturbation of the normal vaginal microbiota, and culture-based identification of single "marker" organisms lacks sensitivity and specificity [23]. Additionally, many of the key organisms that are associated with BV are obligate anaerobes that are either difficult to recover or unrecoverable using conventional culture methods, which makes a true evaluation of vaginal microbiota using culture impossible [6].

The true extent of the microbial diversity in BV was indicated only with the advent of recent cultivation-independent molecular-based approaches, such as polymerase chain reaction (PCR), multiplex-PCR (M-PCR), real-time PCR, taxondirected PCR, broad-range bacterial 16S rDNA PCR, and fluorescence in situ hybridization (FISH) [10, 23-30]. These techniques demonstrated the association of several novel bacteria with BV [29]. Actually, common bacterial vaginosisassociated agents (BV-AAs) include Gardnerella vaginalis, Mobiluncus spp., Mycoplasma hominis, Atopobium vaginae, and Bacteroides fragilis, wherein the presence of $G$. vaginalis and $A$. vaginae together in high copy numbers has a high sensitivity (95\%) and specificity (99\%) for the prediction of BV $[10,24,31]$. BV-AAs include Clostridia-like bacteria vaginosis-associated bacteria (BVABs) 1, 2, and 3, Sneathia spp., Megasphaera type I, Ureaplasma urealyticum, and Mycoplasma genitalium [10, 32-36]. Fredricks et al. [32] demonstrated that the presence of BVAB 2 or Megasphaera type I has a sensitivity of $100 \%$ and specificity of $91.3 \%$ for the prediction of BV. Ling et al. [10] showed that Megasphaera type I and Sneathia spp. were detected at a higher prevalence and higher relative abundance in women with BV.

We report a validated M-PCR diagnostic assay to simultaneous screen for thirteen BV-AAs related to BV: Gardnerella vaginalis, Mobiluncus curtisii, Mobiluncus mulieris, Bacteroides fragilis, Mycoplasma hominis, Atopobium vaginae, Ureaplasma urealyticum, Megasphaera type I, BVAB 1, BVAB 2, BVAB 3, Sneathia sanguinegens, and Mycoplasma genitalium. We believe that M-PCR will potentially impact the diagnostics of $\mathrm{BV}$ and diminish the associated complications in the near future.

\section{Materials and Methods}

2.1. Study Population and Sample Collection. From February 2013 to March 2014, 223 unselected women who attended the Clinical and Research Laboratory (LEPAC) of the State University of Maringá (UEM)/Brazil for regular cervical cancer screening (Pap) upon doctor referral who agreed to participate and fulfilled the inclusion criteria were enrolled in the study. Accordingly, all women were nonpregnant, of reproductive age (range, 15-54 years; mean, 34 years; median, 32 years), had not been using antimicrobials (oral or topical) within the previous 4 weeks, and had not been using an intrauterine device or contraceptives delivered directly to the vaginal mucosa. The Committee for Ethics in Research Involving Humans at the State University of Maringá (UEM)/Paraná, Brazil, approved this study (number 085/2011 and number 104/2012), and each woman involved signed a consent form.

Gram stains of vaginal fluid were not performed routinely on subjects from the LEPAC, in which the patients were recruited. This analysis is performed only upon medical request. Therefore, we included initially 45 samples from women with previous BV diagnosis using Nugent criteria (maximum 15 days prior to study collection), who had not yet received treatment, to standardize the M-PCR method to simultaneous screen for thirteen BV-AAs. Subsequently, the remaining 178 samples were included to validate the assay, and a total of 223 samples from an equal number of women were included.

Vaginal samples for molecular analysis were collected using Ayre's spatula prior to collection of Pap and Gram smears. Samples were transferred to tubes containing $1.0 \mathrm{~mL}$ of sterile $0.9 \% \mathrm{NaCl}$ solution and immediately stored at $-80^{\circ} \mathrm{C}$ until DNA extraction.

\subsection{Multiplex-PCR for the Detection of Thirteen BV-AAs}

2.2.1. Genomic DNA Extraction. An AxyPrep Body Fluid Viral DNA/RNA Miniprep Kit (Axygen, CA, USA) was used according to the manufacturer's instructions. The quality and quantity of purified DNA were measured using spectrophotometry (NanoDrop 2000 Spectrophotometer, Thermo Scientific, Wilmington, USA).

2.2.2. Design of Primers. The thirteen primers were selected from published papers [24, 37-44]. Specificity was checked against all sequences in GenBank using SeqSearch, and primers were aligned by using the Clustal X program (version 1.81, NCBI, Bethesda, MD). Subsequently, all primers were evaluated by performing a Basic Local Alignment Search Tool (BLAST) analysis against the sequences in the NCBI database. The primers were approved when there are no mistakes in their critical regions (e.g., no mismatch at the $3^{\prime}$ end of a primer). All selected primers were designed to have similar physical characteristics to allow simultaneous amplification in a multiplex reaction without the loss of sensitivity and easy separation using gel electrophoresis as follows: melting temperatures $\left(55^{\circ} \mathrm{C}\right.$ to $\left.65^{\circ} \mathrm{C}\right)$, length (18- to 26-base pair-bp), and amplicon sizes ( 80 to $842 \mathrm{bp}$ ) (Table 1$)$.

To assess the specificity of the primers, all primers were also tested in either a sPCR or M-PCR reactions with different samples. No cross-reactivity among the all primers was observed upon amplification of clinical samples that tested positive for any of the 13 bacteria by routine diagnostic analysis.

2.2.3. $M-P C R$ Conditions. Different parameters (magnesium chloride- $\mathrm{MgCl}_{2}$ and primers concentration, annealing and extension temperatures, and number of cycles) were tested in 
TABLE 1: Nucleotide sequences of amplification primers used in the M-PCR.

\begin{tabular}{|c|c|c|c|}
\hline BV-AAs/primers & Sequence $\left(5^{\prime}-3^{\prime}\right)$ & Amplicon size (bp) & Reference or source $^{*}$ \\
\hline \multicolumn{4}{|c|}{ M-PCR assay 1} \\
\hline Mobiluncus curtisii & & & {$[37]$} \\
\hline $\begin{array}{l}\text { Forward } \\
\text { Reverse }\end{array}$ & $\begin{array}{l}\text { GCCAGCCTTCGGGGTGGTGT } \\
\text { TCACGAGTCCCCGGCCGAACC }\end{array}$ & 130 & \\
\hline Ureaplasma urealyticum & & & {$[38]$} \\
\hline $\begin{array}{l}\text { Forward } \\
\text { Reverse }\end{array}$ & $\begin{array}{l}\text { AGAAGACGTTTAGCTAGAGG } \\
\text { ACGACGTCCATAAGCAACT }\end{array}$ & 541 & \\
\hline Mycoplasma hominis & & & {$[39]$} \\
\hline $\begin{array}{l}\text { Forward } \\
\text { Reverse }\end{array}$ & $\begin{array}{l}\text { ATACATCGATGTCGAGCGAG } \\
\text { CATCTTTTAGTGGCGCCTTAC }\end{array}$ & 270 & \\
\hline Gardnerella vaginalis & & & {$[40]$} \\
\hline $\begin{array}{l}\text { Forward } \\
\text { Reverse }\end{array}$ & $\begin{array}{l}\text { TTACTGGTGTATCACTGTAA } \\
\text { CCGTCACAGGCTGAACAGT }\end{array}$ & 330 & \\
\hline Megasphaera type 1 & & & {$[41]$} \\
\hline $\begin{array}{l}\text { Forward } \\
\text { Reverse }\end{array}$ & $\begin{array}{l}\text { GATGCCAACAGTATCCGTCCG } \\
\text { CCTCTCCGACACTCAAGTTCGA }\end{array}$ & 211 & \\
\hline Bacteroides fragilis & & & {$[42]$} \\
\hline $\begin{array}{l}\text { Forward } \\
\text { Reverse }\end{array}$ & $\begin{array}{l}\text { TTCGCTTTTCTGTTTTCTGTGT } \\
\text { CAGCAACCACCCAAACATTATT }\end{array}$ & 842 & \\
\hline \multicolumn{4}{|c|}{ M-PCR assay 2} \\
\hline Atopobium vaginae & & & {$[43]$} \\
\hline $\begin{array}{l}\text { Forward } \\
\text { Reverse }\end{array}$ & $\begin{array}{l}\text { TAGGTCAGGAGTTAAATCTG } \\
\text { TCATGGCCCAGAAGACCGCC }\end{array}$ & 155 & \\
\hline BVAB1 & & & {$[41]$} \\
\hline $\begin{array}{l}\text { Forward } \\
\text { Reverse }\end{array}$ & $\begin{array}{l}\text { GGAGTGTAGGCGGCACTA } \\
\text { CTCTCCGATACTCCAGCTCTA }\end{array}$ & 90 & \\
\hline BVAB2 & & & {$[41]$} \\
\hline $\begin{array}{l}\text { Forward } \\
\text { Reverse }\end{array}$ & $\begin{array}{l}\text { TTAACCTTGGGGTTCATTACAA } \\
\text { GAATACTTATTGTGTTAACTGCGC }\end{array}$ & 260 & \\
\hline \multicolumn{4}{|c|}{ M-PCR assay 3} \\
\hline BVAB3 & & & {$[41]$} \\
\hline $\begin{array}{l}\text { Forward } \\
\text { Reverse }\end{array}$ & $\begin{array}{l}\text { CATTTAGTTGGGCACTCAGGC } \\
\text { ACATTTGGGGATTTGCTTCGCC }\end{array}$ & 160 & \\
\hline Mycoplasma genitalium & & & {$[44]$} \\
\hline $\begin{array}{l}\text { Forward } \\
\text { Reverse }\end{array}$ & $\begin{array}{l}\text { ACCTTGATGGTCAGCAAAACTT } \\
\text { CCTTTGATCTCATTCCAATCAGTA }\end{array}$ & 193 & \\
\hline Mobiluncus mulieris & & & {$[24]$} \\
\hline $\begin{array}{l}\text { Forward } \\
\text { Reverse }\end{array}$ & $\begin{array}{l}\text { ATGGATATGCGTGTGGATGG } \\
\text { CCAGGCATGTAAGCCCAAA }\end{array}$ & 80 & \\
\hline Sneathia sanguinegens & & & {$[41]$} \\
\hline $\begin{array}{l}\text { Forward } \\
\text { Reverse }\end{array}$ & $\begin{array}{l}\text { AATTATTGGGCTTAAAGGGCATC } \\
\text { AGTACTCTAGTTATACAGTTTTGTAG }\end{array}$ & 102 & \\
\hline
\end{tabular}

different combinations. Different annealing temperatures for the primers were found, and we split our analysis into three M-PCR assays.

M-PCR assay 1 was standardized to detect six BV-AAs: $G$. vaginalis, $M$. curtisii, B. fragilis, M. hominis, U. urealyticum, and $M$. type I. Assay 2 detected three BV-AAs: A. vaginae,
BVAB 1, and BVAB 2. Assay 3 detected four BV-AAs: $M$. mulieris, BVAB 3, S. sanguinegens, and $M$. genitalium. The annealing temperatures for each assay were $55^{\circ} \mathrm{C}, 62^{\circ} \mathrm{C}$, and $63^{\circ} \mathrm{C}$, respectively.

The optimized protocol for each assay was a mixture of $25 \mu \mathrm{L}$ containing $2.5 \mathrm{mM}$ of each of the deoxynucleotide 
triphosphates (dNTP), $0.6 \mathrm{mM}$ of $\mathrm{MgCl}_{2}, 25 \mathrm{mM}$ of each primer, $5 \mu \mathrm{L}$ of extracted DNA (50 ng of total sample), and $1 \mathrm{U}$ of Platinum Taq DNA polymerase (Invitrogen, CA, USA). The PCR conditions were comprised of thirty-five amplification cycles of denaturation for $10 \mathrm{~min}$ at $94^{\circ} \mathrm{C}$, annealing for $1 \mathrm{~min}$ with variable temperature depending on the assay $\left(55^{\circ} \mathrm{C}\right.$ or $62^{\circ} \mathrm{C}$ or $63^{\circ} \mathrm{C}$ ), extension for $1 \mathrm{~min}$ at $72^{\circ} \mathrm{C}$, and final extension for $10 \mathrm{~min}$ at $72^{\circ} \mathrm{C}$ (Thermal cycler, Biosystem, CA, USA). M-PCR products were electrophoresed in $8 \%$ polyacrylamide gel stained with $1 \mu \mathrm{g} / \mathrm{mL}$ ethidium bromide.

Positive controls for all studied BV-AAs were derived from positive clinical samples that were detected using reference methods, including culture and/or single PCR (sPCR). sPCR was also performed for the thirteen bacteria in all samples studied and positive controls using the same primers as the M-PCR for standardization and validation. sPCR (gold standard) is generally more sensitive than M-PCR, and crossreactivity, which can occur during M-PCR, is avoided [45]. However, coamplification of the human $\beta$-globin gene using specific primers GH20/PC04 was performed in all clinical samples and controls as an internal control for amplification to ensure that amplifiable DNA was successfully extracted from the samples and monitored for PCR inhibitors under the same conditions as the M-PCR or sPCR reactions [46].

2.3. sPCR. sPCR was performed using the same primers as those used in the M-PCR and the assay consisted of $15 \mu \mathrm{L}$ containing $2.5 \mathrm{mM}$ of each dNTP, $0.6 \mathrm{mM}$ of $\mathrm{MgCl}_{2}, 25 \mathrm{mM}$ of each primer, $5 \mu \mathrm{L}$ of extracted DNA (50 ng of total sample), and $1 \mathrm{U}$ of Taq DNA polymerase (Invitrogen, CA, USA). The PCR conditions were comprised of thirty-five amplification cycles of denaturation for $10 \mathrm{~min}$ at $94^{\circ} \mathrm{C}$, annealing for $1 \mathrm{~min}$ at variable temperatures (depending on the BV-AAs temperature used in assay of $\mathrm{M}-\mathrm{PCR}$, being $55^{\circ} \mathrm{C}, 62^{\circ} \mathrm{C}$, or $63^{\circ} \mathrm{C}$ ), extension for $1 \mathrm{~min}$ at $72^{\circ} \mathrm{C}$, and final extension for $10 \mathrm{~min}$ at $72^{\circ} \mathrm{C}$ (Thermal cycler, Biosystem, CA, USA). The amplification fragments were electrophoresed in $8 \%$ polyacrylamide gel stained with $1 \mu \mathrm{g} / \mathrm{mL}$ ethidium bromide.

2.4. $\beta$-Globin PCR. To assess inhibition, sample adequacy, and integrity, each subject's extracted DNA was subjected to a coamplification of the human $\beta$-globin gene using primers GH20 ( $5^{\prime}$-GAAGAGCCAAGGACAGGTAC- $\left.3^{\prime}\right)$ and PC0 4 ( $5^{\prime}$-CAACTTCATCCACGTTCACC- $\left.3^{\prime}\right)$, under the same conditions as M-PCR or sPCR.

Two types of controls were also included in each reaction series (M-PCR, sPCR, and $\beta$-globin PCR), a "no-DNA" (negative control) and "HPV-positive DNA" (positive control).

2.5. Statistical Analysis. Statistical analysis was performed using Open Source Epidemiologic Statistics for Public Health/OpenEpi, Version 2.3.1. All variables were expressed as absolute and relative frequencies.

\section{Results}

3.1. M-PCR Assay Overall Performance. The M-PCR assay clearly distinguished and identified all thirteen BV-AAs in vaginal samples, whether only one (1 bacterium) or simultaneous bacteria ( 2 or more) were present, and false-positive results were not detected. Final results were regarded as true positives if the sPCR was also positive (gold standard).

The overall agreement of M-PCR results with sPCR was $99.1 \%$, and the validation parameters were as follows: $100.0 \%$ sensitivity, specificity, and positive predictive value, $97.0 \%$ negative predictive value, and $99.3 \%$ accuracy. Individual analyses revealed that $G$. vaginalis, Megasphaera type I, BVAB 1, U. urealyticum, BVAB 3, M. curtisii, A. vaginae, S. sanguinegens, M. mulieris, B. fragilis, and M. genitalium showed values of $100.0 \%$ for all parameters of M-PCR. M-PCR showed $100.0 \%$ specificity and positive predictive values and $98.0 \%$ accuracy for both BVAB 2 and M. hominis agents. These agents differed in sensitivity $(80.0 \%$ and $88.8 \%$, resp.) and negative predictive value (97.8\% and $97.6 \%$, resp.) (Table 2). Figure 1 shows the electrophoretic analyses of the amplified fragments using M-PCR in $8 \%$ polyacrylamide gel of positive samples for different BV-AAs.

3.2. M-PCR Assay Performance in Initial BV Positive Samples. The agreement of M-PCR with Nugent results was $100.0 \%$ because all 45 samples from women with previous BV diagnosis (Nugent criteria; score used: inclusion of abnormal and intermediate groups as positive BV diagnosis) initially included for M-PCR standardization showed BV-AAs.

In these 45 samples, 20 (44.5\%) had only one BV-AAs; 10 (22.2\%) had 2 simultaneous BV-AAs; 6 (13.3\%) had 3 simultaneous BV-AAs; 6 (13.3\%) had 4 simultaneous BV-AAs; $2(4.4 \%)$ had 5 simultaneous BV-AAs; and 1 (2.2\%) had 6 simultaneous BV-AAs. The most common BV-AAs detected as a single agent or simultaneously in these samples were Megasphaera type I $(n=21,46.7 \%)$, followed by $G$. vaginalis $(n=14,31.1 \%), M$. curtisii, and BVAB $2(n=12,26.7 \%$ each). Bacteroides fragilis was not detected. Table 3 shows the M-PCR results for BV-AAs as single agent or simultaneously (two or more agents) in the 45 initially analyzed samples.

3.3. BV-AA Positivity in All Samples Analyzed. BV-AAs were detected in 162 of the 223 samples $(72.6 \%)$ as a single agent or simultaneously. The most frequent BV-AA was $G$. vaginalis ( $n=74$ ), which was detected in $45.7 \%$ of the positive samples, followed by $M$. type I $(n=52 ; 32.1 \%)$, BVAB $1(n=35 ; 21.6 \%)$, U. urealyticum $(n=28 ; 17.3 \%)$, BVAB $3(n=27 ; 16.7 \%), M$. curtisii $(n=22 ; 13.6 \%)$, BVAB $2(n=20 ; 12.3 \%)$, A. vaginae $(n=15 ; 9.3 \%), M$. hominis and $S$. sanguinegens $(n=9 ; 5.5 \%$, each), M. mulieris $(n=6 ; 3.7 \%), B$. fragilis $(n=4 ; 2.5 \%)$, and M. genitalium ( $n=2 ; 1.2 \%)$ (Figure 2 ).

3.4. BV-AA Positivity as a Single Agent. Only one BV-AA was detected in 76 of the 162 positive samples (46.9\%), which represented $34.1 \%$ of the total samples studied. The most frequent agent in these cases was $G$. vaginalis $(n=31 ; 40.8 \%)$, followed by $M$. type I $(n=14 ; 18.4 \%), U$. urealyticum $(n=11$; $14.5 \%)$, M. curtisii $(n=6 ; 7.9)$, and M. hominis $(n=4 ; 5.3 \%)$.

3.5. Simultaneous BV-AA Detection. Two or more BV-AAs were detected simultaneously in the remaining 86 BV-AApositive samples $(53.1 \%)$, which represented $38.6 \%$ of the total 
TABLE 2: M-PCR validation based compared to sPCR for thirteen major BV-AAs in cervical-vaginal samples.

\begin{tabular}{|c|c|c|c|c|c|}
\hline Agents & Sensibility (\%) & Specificity (\%) & PPV (\%) & NPV (\%) & Accuracy (\%) \\
\hline Overall & 99.1 & 100.0 & 100.0 & 97.0 & 99.3 \\
\hline Mobiluncus curtisii & 100.0 & 100.0 & 100.0 & 100.0 & 100.0 \\
\hline Ureaplasma urealyticum & 100.0 & 100.0 & 100.0 & 100.0 & 100.0 \\
\hline Mycoplasma hominis & 80.0 & 100.0 & 100.0 & 97.8 & 98.0 \\
\hline Gardnerella vaginalis & 100.0 & 100.0 & 100.0 & 100.0 & 100.0 \\
\hline Megasphaera type 1 & 100.0 & 100.0 & 100.0 & 100.0 & 100.0 \\
\hline Bacteroides fragilis & 100.0 & 100.0 & 100.0 & 100.0 & 100.0 \\
\hline Atopobium vaginae & 100.0 & 100.0 & 100.0 & 100.0 & 100.0 \\
\hline BVAB1 & 100.0 & 100.0 & 100.0 & 100.0 & 100.0 \\
\hline BVAB2 & 88.8 & 100.0 & 100.0 & 97.6 & 98.0 \\
\hline BVAB3 & 100.0 & 100.0 & 100.0 & 100.0 & 100.0 \\
\hline Mycoplasma genitalium & 100.0 & 100.0 & 100.0 & 100.0 & 100.0 \\
\hline Mobiluncus mulieris & 100.0 & 100.0 & 100.0 & 100.0 & 100.0 \\
\hline Sneathia sanguinegens & 100.0 & 100.0 & 100.0 & 100.0 & 100.0 \\
\hline Two or more agents simultaneously & 100.0 & 100.0 & 100.0 & 100.0 & 100.0 \\
\hline
\end{tabular}

M-PCR: multiplex polymerase chain reaction; sPCR: single polymerase chain reaction; BV-AAs: bacterial vaginosis-associated agents; PPV: positive predictive value; NPV: negative predictive value.

samples studied. Fifty of these samples (30.9\%) showed two simultaneous BV-AAs, which represent $58.1 \%$ of all samples with detected simultaneous BV-AAs. The most frequent associations included G. vaginalis + BVAB $1(n=7 ; 14.0 \%), U$. urealyticum + G. vaginalis $(n=5 ; 10.0 \%), M$. type $\mathrm{I}+\mathrm{BVAB}$ 1 , and $M$. type $I+G$. vaginalis $(n=4 ; 8.0 \%$, each).

Three simultaneous BV-AAs were detected in 22 samples, which represented $13.6 \%$ of BV-AA-positive samples, $25.6 \%$ of total samples with simultaneous BV-AAs and $9.9 \%$ of the total samples studied. The most frequent associations were $A$. vaginae + BVAB 2 + BVAB 3 and G. vaginalis + M. curtisii + $M$. type I ( $n=2 ; 9.0 \%$, each).

Four simultaneous BV-AAs were detected in 11 samples, which represented $6.8 \%$ of BV-AA-positive samples, $12.8 \%$ of the total samples with simultaneous BV-AAs and $4.9 \%$ of the total samples studied. The most frequent association was $U$. urealyticum $+G$. vaginalis $+M$. type I + BVAB $1(n=2$; 18.2\%).

Five simultaneous BV-AAs were detected in 2 samples, which represented $1.2 \%$ of positive BV-AA samples, $2.3 \%$ of total samples with simultaneous BV-AAs and $0.9 \%$ of the total samples studied. The associations were $M$. curtisii $+M$. type $\mathrm{I}+\mathrm{BVAB} 3+M$. mulieris $+S$. sanguinegens and $U$. urealyticum + G. vaginalis + A. vaginae + BVAB $1+$ BVAB 2 . Six simultaneous BV-AAs were detected in 1 sample, which represented $0.6 \%$ of positive BV-AA samples, $1.2 \%$ of total samples with simultaneous BV-AAs, and $0.4 \%$ of the total samples studied. The association was G. vaginalis $+M$. curtisii $+M$. type I + A. vaginae + BVAB $2+$ M. mulieris.

\section{Discussion}

To our knowledge, this is the first study to simultaneously screen for thirteen of the BV-AAs that are most related to $B V$ in vaginal samples using M-PCR in Brazil and Latin America. Our study did not aim to identify or evaluate
BV-AAs alone or in combination as markers of BV, but we sought to standardize and validate an M-PCR assay for the screening of populations in which the complications of $\mathrm{BV}$ may be more severe. The overall agreement of M-PCR with sPCR was elevated (99.1\%), and other validation parameters, including sensitivity, specificity, positive and negative predictive value, and accuracy, were also excellent (ranging from $99.3 \%$ to $100 \%$ ). M-PCR also showed excellent values for all parameters for the individual identification of BV-AAs, and M-PCR detected 86 cervical samples (53.0\%) with two or more BV-AAs simultaneously. The agreement of M-PCR results with the Nugent method was $100.0 \%$. Importantly, in the three M-PCR assays were used primers published in other studies without modification for all bacteria, but previously checked against all sequences in GenBank and evaluated by performing a BLAST analysis.

The application of this panel of 13 BV-AAs-targeted PCR assay to vaginal samples serves several purposes. First, these data help establish the bacterial compositions of the human cervix and vagina in subjects with and without BV and validate our earlier findings in smaller group BV-positive subjects using the Nugent method $(n=45)$. Second, the recent use of molecular microbial detection methods in wellcharacterized subjects established that a large portion of the vaginal microbiota in subjects with $\mathrm{BV}$ is derived from bacteria that appear to be novel and uncultivated $[6,27$, 34]. To overcome this limitation, we developed a highly sensitive M-PCR assay targeting particular bacterial species that were previously detected in other molecular studies. Our approach will clearly not detect new species, but it is helpful in determining the true frequencies of key vaginal bacteria, which is a critical first step in understanding how vaginal bacteria interact with each other and the human host. Finally, rapid PCR assays may allow the microbiological diagnosis of BV in clinics [34] and clinical laboratories. The M-PCR assay is very sensitive assay that simplifies 
TABLE 3: M-PCR assay performance in 45 initial samples analyzed from women with BV diagnosis by Nugent criteria.

\begin{tabular}{|c|c|c|}
\hline BV-AAs detected & $n$ & $\%$ \\
\hline Only one BV-AA & 20 & 44.5 \\
\hline Megasphaera type I & 9 & 45.0 \\
\hline Mobiluncus curtisii & 6 & 30.0 \\
\hline Gardnerella vaginalis & 4 & 20.0 \\
\hline Mycoplasma hominis & 1 & 5.0 \\
\hline 2 simultaneous BV-AAs & 10 & 22.2 \\
\hline Ureaplasma urealyticum + Gardnerella vaginalis & 2 & 20.0 \\
\hline Megasphaera type I + BVAB 1 & 2 & 20.0 \\
\hline Mobiluncus curtisii + BVAB 1 & 1 & 10.0 \\
\hline Megasphaera type I + M. hominis & 1 & 10.0 \\
\hline Megasphaera type I + Atopobium vaginae & 1 & 10.0 \\
\hline Mycoplasma hominis + Sneathia sanguinegens & 1 & 10.0 \\
\hline Gardnerella vaginalis + BVAB 3 & 1 & 10.0 \\
\hline Mobiluncus curtisii + BVAB 2 & 1 & 10.0 \\
\hline 3 simultaneous BV-AAs & 6 & 13.3 \\
\hline Megasphaera type I + BVAB $1+$ BVAB 3 & 2 & 33.3 \\
\hline Gardnerella vaginalis + BVAB $2+$ BVAB 3 & 1 & 16.6 \\
\hline Mobiluncus curtisii + BVAB $1+$ BVAB 3 & 1 & 16.6 \\
\hline Megasphaera type I + BVAB $2+$ BVAB 3 & 1 & 16.6 \\
\hline Gardnerella vaginalis + Atopobium vaginae + BVAB 2 & 1 & 16.6 \\
\hline 4 simultaneous BV-AAs & 6 & 13.3 \\
\hline Megasphaera type I + Atopobium vaginae + BVAB $2+$ Sneathia sanguinegens & 1 & 16.6 \\
\hline Gardnerella vaginalis + Mobiluncus curtisii + BVAB $2+$ Sneathia sanguinegens & 1 & 16.6 \\
\hline Gardnerella vaginalis + Mobiluncus curtisii + BVAB $2+$ Atopobium vaginae & 1 & 16.6 \\
\hline Gardnerella vaginalis + Atopobium vaginae + BVAB $2+$ BVAB 3 & 1 & 16.6 \\
\hline Megasphaera type I + Atopobium vaginae + BVAB $2+$ BVAB 3 & 1 & 16.6 \\
\hline Megasphaera type I + BVAB $3+$ Mobiluncus mulieris + Sneathia sanguinegens & 1 & 16.6 \\
\hline 5 simultaneous BV-AAs & 2 & 4.4 \\
\hline Ureaplasma urealyticum + Gardnerella vaginalis + Atopobium vaginae + BVAB $1+$ BVAB 2 & 1 & 50.0 \\
\hline Mobiluncus curtisii + Megasphaera type I + BVAB $3+$ Mobiluncus mulieris + Sneathia sanguinegens & 1 & 50.0 \\
\hline 6 simultaneous BV-AAs & 1 & 2.2 \\
\hline Gardnerella vaginalis + Mobiluncus curtisii + Megasphaera type I + Atopobium vaginae + BVAB $2+$ Mobiluncus mulieris & 1 & 100.0 \\
\hline
\end{tabular}

M-PCR: multiplex polymerase chain reaction; BV: bacterial vaginosis; BV-AAs: bacterial vaginosis-associated agents; BVABs 1, 2, and 3, bacterial vaginosisassociated bacteria 1,2 , and 3 .

workflow and reduces costs and time, which allows for its use in routine diagnostic laboratories with basic molecular facilities [47-50]. Furthermore, application of the M-PCR assay will potentiate the diagnostics of BV-AAs because thirteen agents can be detected independently of the clinical status of women, wherein many of these BV-AAs are difficult to identify using conventional methods. We detected BVAAs as single or simultaneous agents in 162 women from a total of 223. Therefore, this M-PCR assay has great potential for application in screening for BV-AAs in both pregnant and nonpregnant women as early as possible to prevent complications, such as PID $[7,8]$ and subsequent infertility [9], increased risk of preterm labor and delivery $[9,10]$, amniotic fluid infections [11], chorioamnionitis [12], low birth weight [13], endometritis [14], cervicitis [15], and increased susceptibility to infection with various pathogens, such as Neisseria gonorrhoeae, Chlamydia trachomatis, Trichomonas vaginalis, Herpes Simplex type-2 (HSV-2), and HIV $[5,16]$. Below, we discuss only the frequency of the detected BVAAs, recalling that our study did not aim to find or evaluate $\mathrm{BV}$-AAs alone or in combination as markers of BV but to standardize and validate the use of the M-PCR assay.

The initial 45 samples were positive BV using the Nugent method, and the following BV-AAs were detected as a single agent or simultaneously: Megasphaera type I (46.7\%), followed by $G$. vaginalis (31.1\%), M. curtisii, and BVAB 2 (26.7\% each). When all samples were studied together, the most prevalent BV-AAs detected were G. vaginalis $(45.7 \%)$, followed by $M$. type I (32.1\%), BVAB 1 (21.6\%), U. urealyticum (17.3), BVAB 3 (16.7\%), and M. curtisii (13.6\%). Therefore, BVAAs were detected more often individually in both samples, with the exception of $U$. urealyticum.

Cultivation methods failed to unequivocally identify a specific bacterial pathogen or unique pathogenic community 


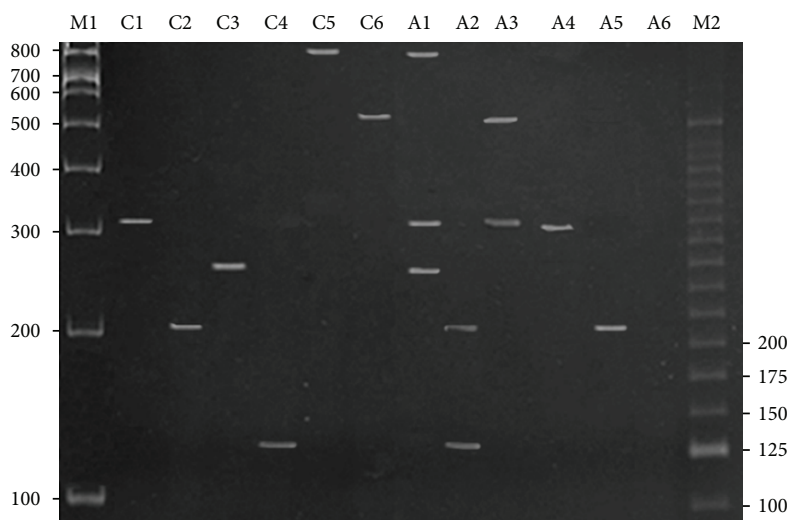

(a) M-PCR assay 1

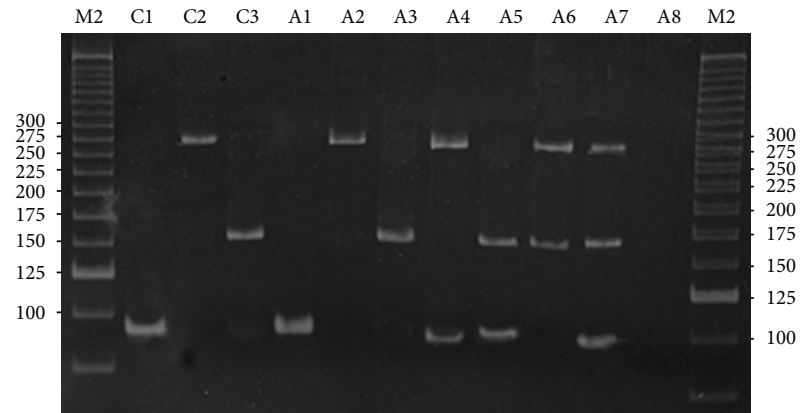

(b) M-PCR assay 2

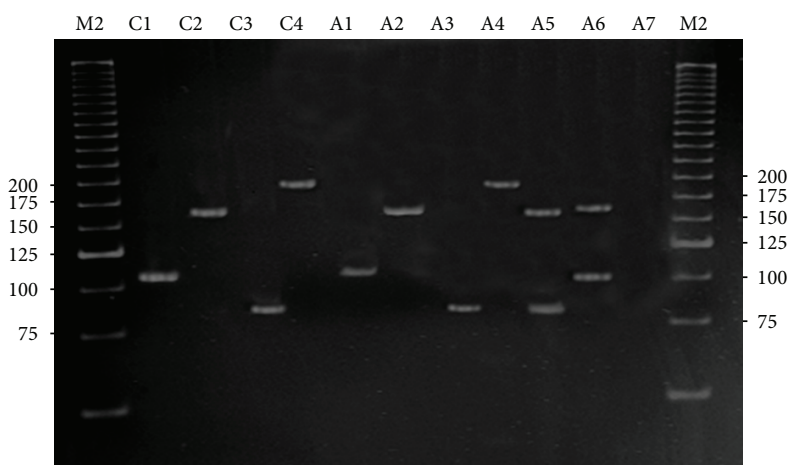

(c) M-PCR assay 3

FIGURE 1: Electrophoretic analysis of the amplified fragments by using M-PCR in 8\% polyacrylamide gels. Positive control (C). (a) M-PCR assay 1: C1: Gardnerella vaginalis (330 base pairs-bp); C2: Megasphaera type I (211 pb); C3: Mycoplasma hominis (270 pb); C4: Mobiluncus curtisii (130 pb); C5: Bacteroides fragilis (842 pb); C6: Ureaplasma urealyticum (541 pb); A1: positive sample for B. fragilis, G. vaginalis and M. hominis; A2: positive sample for M. type I and M. curtisii; A3: positive sample for U. urealyticum and G. vaginalis; A4: positive sample for G. vaginalis; A5: positive sample for $M$. type I (211 pb); A6: negative control. (b) M-PCR assay 2: C1: BVAB 1 (90 bp); C2: BVAB 2 (260 pb); C3: Atopobium vaginae (155 pb); A1: positive sample for BVAB 1; A2: positive sample for BVAB 2; A3: positive sample for A. vaginae; A4: positive sample for BVAB 2 and BVAB 1; A5: positive sample for A. vaginae and BVAB 1; A6: positive sample for BVAB 2 and A. vaginae; A7: positive sample of BVAB 2, A. vaginae and BVAB 1; A8: negative control. (c) M-PCR assay 3: C1: Sneathia sanguinegens (102 bp); C2: BVAB 3 (160 pb); C3: Mobiluncus mulieris (80 pb); C4: Mycoplasma genitalium (193 pb); A1: positive sample for S. sanguinegens (102 bp); A2: positive sample for BVAB 3; A3: positive sample of Mobiluncus mulieris; A4: positive sample of M. genitalium; A5: positive sample of BVAB 3 and M. mulieris; A6: positive sample for BVAB 3 and S. sanguinegens; A7: negative control. Lanes M1: molecular weight marker (100 bp); M2: molecular weight marker (25 bp).

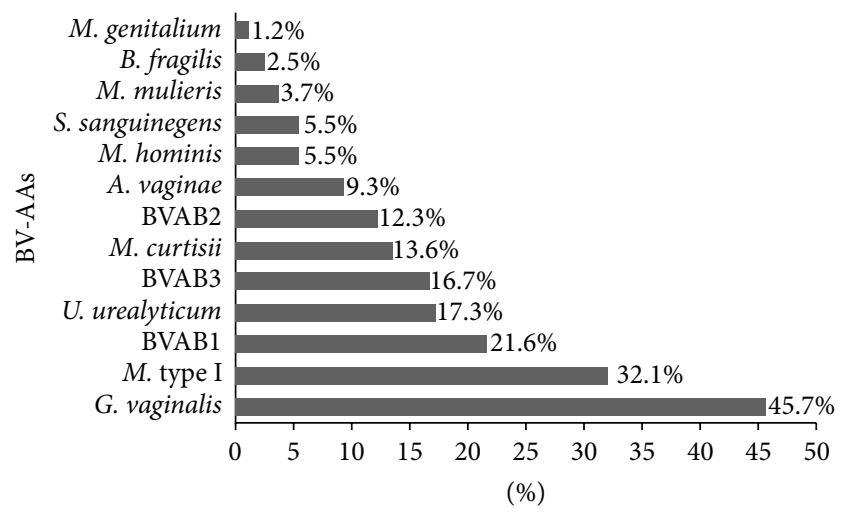

FIGURE 2: Frequency of thirteen major bacterial vaginosisassociated agents (BV-AAs) in all 223 samples studied as single agents or simultaneous detection. in subjects with BV. Therefore, it had been hypothesized that several of the uncultivated bacteria associated with $\mathrm{BV}$ that were detected using PCR would be more reliable indicators of $\mathrm{BV}$ than the cultivated bacteria previously linked to this condition [34]. Our study obtained elevated values of validation parameters and detected that $53.1 \%$ of BV-AA-positive samples included two or more BV-AAs simultaneously: $30.9 \%$ showed two simultaneous bacteria, $25.6 \%$ three, $12.8 \%$ four, $2.3 \%$ five, and $1.2 \%$ six. Therefore, this assay will be very important to assess associations between bacteria in the vaginal microbiota.

Individual analysis of each of the BV-AAs revealed that the most frequently detected BV-AA as a single or simultaneous agent was $G$. vaginalis $(n=74 ; 45.7 \%)$. Historically, $G$. vaginalis was thought to play the leading role in infection, which created a niche suitable for colonization 
by strict anaerobes, which are largely responsible for the clinical symptoms of BV [49-51]. Recent published findings suggested that $G$. vaginalis biofilms may be critical in BV pathogenesis and symptomatology [24]. However, the detection of only one bacteria type is not a specific marker of BV because it may be commonly present in women with normal vaginal flora, although generally in smaller numbers than in women with BV $[6,27,52]$.

Megasphaera type I was the second most frequent BV$\mathrm{AA}(32.1 \%)$, and the third most frequent was BVAB $1(n=$ $35 ; 21.60 \%)$. $M$. type I is an anaerobic bacterium similar to lactobacilli that produces lactic acid, which is strongly related to BV and correlated significantly with increased sexual exposure [27]. Fredricks et al. [34] reported that these bacteria are excellent markers of $\mathrm{BV}$ either alone or in combination with other BV-AAs. Fethers et al. [27] showed that the detection of the combination of either $M$. type I or one of the Clostridiales bacteria (BVAB 1-3) using PCR yielded a sensitivity of $99 \%$ and a specificity of $89 \%$ for the diagnosis of BV $[27,34]$. The other BVABs (2 and 3) were detected in the present study at a lower frequency than BVAB $1(12.3 \%$ and $16.7 \%$ of samples, resp.). A previous study showed that the detection of BVAB (1-3) was highly related to the presence of BV. The presence of BVAB (1-3) resulted in BV a few months after analysis, despite the detection of these bacteria in the vaginal fluid of healthy women [32]. Therefore, our results for the detection of $M$. type I, BVAB 1, BVAB 2, and BVAB 3 supports their importance in BV physiopathology and further demonstrated that our technique has great reliability and potential use for BV screening.

$U$. urealyticum and $M$. curtisii were detected with intermediate frequency $(17.3 \%$, and $13.6 \%$, resp.), and other BVAAs were detected much lesser frequently: A. vaginae (9.2\%), M. hominis, and S. sanguinegens (5.5\%, each), M. mulieris (3.7\%), B. fragilis (2.5\%), and M. genitalium (1.2\%). Different molecular studies do not unanimously identify BV markers with respect to frequencies and the bacterial agents detected. Some findings are more common, but there is a wide variation $[26,27,29]$. For example, Pépin et al. [26] reported that the presence of G. vaginalis, Bifidobacterium, Megasphaera elsdenii, Dialister, M. hominis, Leptotrichia, and Prevotella was independently associated with BV. However, Mobiluncus, A. vaginae, Anaerococcus, and Eggerthella were not independently associated with BV. Fethers et al. [27] reported that only $M$. type I, BVAB 2, A. vaginae, and $G$. vaginalis were significantly associated with BV. Shipitsyna et al. [29] showed that only G. vaginalis, A. vaginae, Eggerthella, Prevotella, BVAB 2, and $M$. type 1 were highly predictable for BV. Twin et al. [53] detected most bacteria of the genus Prevotella (predominately P. amnii), followed by Megasphaera, Leptotrichia/Sneathia, and Fusobacterium (8\%), of which P. amnii was strongly associated with BV. These variations between studies may be influenced by the type of women studied (e.g., pregnant or not; with or without symptoms of BV; with differences in the frequency and type of sexual contact, etc.) or the type of molecular technique used. Therefore, we chose a roster of BV-AAs that are commonly found in women with $\mathrm{BV}$ in previous studies for inclusion in our M-PCR assay.
Our M-PCR assays are qualitative and do not provide information about the quantities of bacteria that are present in subjects with and without BV. The quantity of bacteria may be an important predictor of disease [34]. However, we proposed a technique that is more economically accessible and easier to use as screening tool to benefit women with a molecular diagnosis, even in regions and/or countries with less financial resources. Additionally, we did not attempt to assay every known vaginal bacterium using targeted PCR assays because of practical limitations. We expect that many additional bacterial species are present in vaginal samples from subjects with and without BV. Nevertheless, these results build a foundation to improve our understanding of bacterial diversity in the human vagina.

Our data support that the detection of thirteen BV-AAs using M-PCR provides important information about the frequency of these agents. Additionally, M-PCR should be applied for the diagnosis or confirmation of BV, which would lead to an earlier diagnosis to prevent possible complications in specific women, without the impediments of high cost, long assay times, and difficulties in workflow. Finally, M-PCR provided information to improve our understanding of this syndrome, which may improve the management and optimal medical treatment for women with BV.

\section{Conflict of Interests}

The authors declare that they have no competing interests regarding the publication of this paper.

\section{Acknowledgment}

This work was supported by grants from Coordenação de Aperfeiçoamento de Pessoal de Nível Superior (CAPES), AUX-PE-PRODOC 2571/2010 and PVE A109/2013, Brazilian Government.

\section{References}

[1] J. R. Schwebke, "New concepts in the etiology of bacterial vaginosis," Current Infectious Disease Reports, vol. 11, no. 2, pp. 143-147, 2009.

[2] J. M. Marrazzo, "Interpreting the epidemiology and natural history of bacterial vaginosis: are we still confused?" Anaerobe, vol. 17, no. 4, pp. 186-190, 2011.

[3] M. A. Klebanoff, J. R. Schwebke, J. Zhang, T. R. Nansel, K.-F. Yu, and W. W. Andrews, "Vulvovaginal symptoms in women with bacterial vaginosis," Obstetrics \& Gynecology, vol. 104, no. 2, pp. 267-272, 2004.

[4] E. Gillet, J. F. A. Meys, H. Verstraelen et al., "Bacterial vaginosis is associated with uterine cervical human papillomavirus infection: a meta-analysis," BMC Infectious Diseases, vol. 11, article 10, 2011.

[5] P. Hay, "Bacterial vaginosis," Medicine, vol. 42, no. 7, pp. 359363, 2014.

[6] J. Ravel, P. Gajer, Z. Abdo et al., "Vaginal microbiome of reproductive-age women," Proceedings of the National Academy of Sciences of the United States of America, vol. 108, supplement 1, pp. 4680-4687, 2011. 
[7] J. F. Peipert, R. B. Ness, J. Blume et al., "Clinical predictors of endometritis in women with symptoms and signs of pelvic inflammatory disease," American Journal of Obstetrics \& Gynecology, vol. 184, no. 5, pp. 856-864, 2001.

[8] C. L. Haggerty, S. L. Hillier, D. C. Bass, and R. B. Ness, "Bacterial vaginosis and anaerobic bacteria are associated with endometritis," Clinical Infectious Diseases, vol. 39, no. 7, pp. 990995, 2004.

[9] M. A. Klebanoff, S. L. Hillier, R. P. Nugent et al., "Is bacterial vaginosis a stronger risk factor for preterm birth when it is diagnosed earlier in gestation?" American Journal of Obstetrics \& Gynecology, vol. 192, no. 2, pp. 470-477, 2005.

[10] Z. Ling, J. Kong, F. Liu et al., "Molecular analysis of the diversity of vaginal microbiota associated with bacterial vaginosis," $B M C$ Genomics, vol. 11, no. 1, article 488, 2010.

[11] H. M. Silver, R. S. Sperling, P. J. St. Clair, and R. S. Gibbs, "Evidence relating bacterial vaginosis to intraamniotic infection," American Journal of Obstetrics \& Gynecology, vol. 161, no. 3, pp. 808-812, 1989.

[12] S. L. Hillier, J. Martius, M. Krohn, N. Kiviat, K. K. Holmes, and D. A. Eschenbach, "A case-control study of chorioamnionic infection and histologic chorioamnionitis in prematurity," The New England Journal of Medicine, vol. 319, no. 15, pp. 972-978, 1988.

[13] H. Leitich, B. Bodner-Adler, M. Brunbauer, A. Kaider, C. Egarter, and P. Husslein, "Bacterial vaginosis as a risk factor for preterm delivery: a meta-analysis," American Journal of Obstetrics \& Gynecology, vol. 189, no. 1, pp. 139-147, 2003.

[14] R. L. Sweet, "Gynecologic conditions and bacterial vaginosis: implications for the non-pregnant patient," Infectious Diseases in Obstetrics and Gynecology, vol. 8, no. 3-4, pp. 184-190, 2000.

[15] A. H. N. Ugwumadu, "Bacterial vaginosis in pregnancy," Current Opinion in Obstetrics and Gynecology, vol. 14, no. 2, pp. 115118, 2002.

[16] C. R. Cohen, S. C. Cheng, S. Shiboski et al., "Diaphragm used with replens gel and risk of bacterial vaginosis: results from a randomized controlled trial," Infectious Diseases in Obstetrics and Gynecology, vol. 2012, Article ID 921519, 8 pages, 2012.

[17] R. Chawla, P. Bhalla, S. Chadha, S. Grover, and S. Garg, "Comparison of Hay's criteria with Nugent's scoring system for diagnosis of bacterial vaginosis," BioMed Research International, vol. 2013, Article ID 365194, 5 pages, 2013.

[18] R. M. Brotman and J. Ravel, "Ready or not: the molecular diagnosis of bacterial vaginosis," Clinical Infectious Diseases, vol. 47, no. 1, pp. 44-46, 2008.

[19] R. Amsel, P. A. Totten, C. A. Spiegel, K. C. Chen, D. Eschenbach, and K. K. Holmes, "Nonspecific vaginitis. Diagnostic criteria and microbial and epidemiologic associations," The American Journal of Medicine, vol. 74, no. 1, pp. 14-22, 1983.

[20] R. P. Nugent, M. A. Krohn, and S. L. Hillier, "Reliability of diagnosing bacterial vaginosis is improved by a standardized method of gram stain interpretation," Journal of Clinical Microbiology, vol. 29, no. 2, pp. 297-301, 1991.

[21] H. Bahar, M. M. Torun, F. Öçer, and B. Kocazeybek, "Mobiluncus species in gynaecological and obstetric infections: antimicrobial resistance and prevalence in a Turkish population," International Journal of Antimicrobial Agents, vol. 25, no. 3, pp. 268-271, 2005.

[22] R. T. Gergova, T. V. Strateva, and I. G. Mitov, "Gardnerella vaginalis-associated bacterial vaginosis in Bulgarian women," Brazilian Journal of Infectious Diseases, vol. 17, no. 3, pp. 313-318, 2013.
[23] C. P. Cartwright, B. D. Lembke, K. Ramachandran et al., "Development and validation of a semiquantitative, multitarget PCR assay for diagnosis of bacterial vaginosis," Journal of Clinical Microbiology, vol. 50, no. 7, pp. 2321-2329, 2012.

[24] J.-P. Menard, F. Fenollar, M. Henry, F. Bretelle, and D. Raoult, "Molecular quantification of Gardnerella vaginalis and Atopobium vaginae loads to predict bacterial vaginosis," Clinical Infectious Diseases, vol. 47, no. 1, pp. 33-43, 2008.

[25] C. L. Haggerty, P. A. Totten, M. Ferris et al., "Clinical characteristics of bacterial vaginosis among women testing positive for fastidious bacteria," Sexually Transmitted Infections, vol. 85, no. 4, pp. 242-248, 2009.

[26] J. Pépin, S. Deslandes, G. Giroux et al., "The complex vaginal flora of West African women with bacterial vaginosis," PLoS ONE, vol. 6, no. 9, Article ID e25082, 2011.

[27] K. Fethers, J. Twin, C. K. Fairley et al., "Bacterial vaginosis (BV) candidate bacteria: associations with BV and behavioural practices in sexually-experienced and inexperienced women," PLoS ONE, vol. 7, no. 2, Article ID e30633, 2012.

[28] S. Srinivasan, N. G. Hoffman, M. T. Morgan et al., "Bacterial communities in women with bacterial vaginosis: high resolution phylogenetic analyses reveal relationships of microbiota to clinical criteria," PLoS ONE, vol. 7, no. 6, Article ID e37818, 2012.

[29] E. Shipitsyna, A. Roos, R. Datcu et al., "Composition of the vaginal microbiota in women of reproductive age-sensitive and specific molecular diagnosis of bacterial vaginosis is possible?" PLoS ONE, vol. 8, no. 4, Article ID e60670, 2013.

[30] B. Foxman, A. Wen, U. Srinivasan et al., "Mycoplasma, bacterial vaginosis-associated bacteria BVAB3, race, and risk of preterm birth in a high-risk cohort," American Journal of Obstetrics \& Gynecology, vol. 210, no. 3, pp. 226.e1-226.e7, 2014.

[31] C. H. Livengood, "Bacterial vaginosis: an overview for 2009," Reviews in Obstetrics \& Gynecology, vol. 2, no. 1, pp. 28-37, 2009.

[32] D. N. Fredricks, T. L. Fiedler, and J. M. Marrazzo, "Molecular identification of bacteria associated with bacterial vaginosis," The New England Journal of Medicine, vol. 353, no. 18, pp. 18991911, 2005.

[33] K. Mallard, K. Schopfer, and T. Bodmer, "Development of realtime PCR for the differential detection and quantification of Ureaplasma urealyticum and Ureaplasma parvum," Journal of Microbiological Methods, vol. 60, no. 1, pp. 13-19, 2005.

[34] D. N. Fredricks, T. L. Fiedler, K. K. Thomas, B. B. Oakley, and J. M. Marrazzo, "Targeted PCR for detection of vaginal bacteria associated with bacterial vaginosis," Journal of Clinical Microbiology, vol. 45, no. 10, pp. 3270-3276, 2007.

[35] K. B. Waites, L. Xiao, V. Paralanov, R. M. Viscardi, and J. I. Glass, "Molecular methods for the detection of mycoplasma and ureaplasma infections in humans: a paper from the 2011 William Beaumont Hospital symposium on molecular pathology," Journal of Molecular Diagnostics, vol. 14, no. 5, pp. 437-450, 2012.

[36] J. S. Huppert, J. R. Bates, A. F. Weber, N. Quinn, and C. A. Gaydos, "Abnormal vaginal $\mathrm{pH}$ and Mycoplasma genitalium infection," Journal of Pediatric \& Adolescent Gynecology, vol. 26, no. 1, pp. 36-39, 2013.

[37] A. Tiveljung, U. Forsum, and H.-J. Monstein, "Classification of the genus Mobiluncus based on comparative partial 16S rRNA gene analysis," International Journal of Systematic Bacteriology, vol. 46, no. 1, pp. 332-336, 1996.

[38] D. E. Riley, M. Samadpour, and J. N. Krieger, "Detection of variable DNA repeats in diverse eukaryotic microorganisms by a single set of polymerase chain reaction primers," Journal of Clinical Microbiology, vol. 29, no. 12, pp. 2746-2751, 1991. 
[39] F. A. Nassar, F. A. Abu-Elamreen, M. E. Shubair, and F. A. Sharif, "Detection of Chlamydia trachomatis and Mycoplasma hominis, genitalium and Ureaplasma urealyticum by polymerase chain reaction in patients with sterile pyuria," Advance Medical Science, vol. 53, no. 1, pp. 80-86, 2008.

[40] A. Ingianni, S. Petruzzelli, G. Morandotti, and R. Pompei, "Genotypic differentiation of Gardnerella vaginalis by amplified ribosomal DNA restriction analysis (ARDRA)," FEMS Immunology and Medical Microbiology, vol. 18, no. 1, pp. 61-66, 1997.

[41] D. N. Fredricks, T. L. Fiedler, K. K. Thomas, C. M. Mitchell, and J. M. Marrazzo, "Changes in vaginal bacterial concentrations with intravaginal metronidazole therapy for bacterial vaginosis as assessed by quantitative PCR," Journal of Clinical Microbiology, vol. 47, no. 3, pp. 721-726, 2009.

[42] M. Obata-Yasuoka, W. Ba-Thein, H. Hamada, and H. Hayashi, "A multiplex polymerase chain reaction-based diagnostic method for bacterial vaginosis," Obstetrics and Gynecology, vol. 100, no. 4, pp. 759-764, 2002.

[43] M. J. Ferris, A. Masztal, and D. H. Martin, "Use of speciesdirected 16S rRNA gene PCR primers for detection of Atopobium vaginae in patients with bacterial vaginosis," Journal of Clinical Microbiology, vol. 42, no. 12, pp. 5892-5894, 2004.

[44] C. M. Muvunyi, N. Dhont, R. Verhelst et al., "Evaluation of a new multiplex polymerase chain reaction assay STDFinder for the simultaneous detection of 7 sexually transmitted disease pathogens," Diagnostic Microbiology and Infectious Disease, vol. 71, no. 1, pp. 29-37, 2011.

[45] C. J. McIver, N. Rismanto, C. Smith et al., "Multiplex PCR testing detection of higher-than-expected rates of cervical Mycoplasma, Ureaplasma, and Trichomonas and viral agent infections in sexually active australian women," Journal of Clinical Microbiology, vol. 47, no. 5, pp. 1358-1363, 2009.

[46] D. N. Fredricks and D. A. Relman, "Application of polymerase chain reaction to the diagnosis of infectious diseases," Clinical Infectious Diseases, vol. 29, no. 3, pp. 475-488, 1999.

[47] M. L. Mckechnie, R. Hillman, D. Couldwell et al., "Simultaneous identification of 14 genital microorganisms in urine by use of a multiplex PCR-based reverse line blot assay," Journal of Clinical Microbiology, vol. 47, no. 6, pp. 1871-1877, 2009.

[48] R. P. Souza, A. L. P. de Abreu, É. C. Ferreira et al., "Simultaneous detection of seven sexually transmitted agents in human immunodeficiency virus-infected Brazilian women by multiplex polymerase chain reaction," American Journal of Tropical Medicine and Hygiene, vol. 89, no. 6, pp. 1199-1202, 2013.

[49] F. Gimenes, F. S. Medina, A. L. Abreu et al., "Sensitive simultaneous detection of seven sexually transmitted agents in semen by multiplex-PCR and of HPV by single PCR," PLOS ONE, vol. 9, no. 6, Article ID e98862, 2014.

[50] A. Swidsinski, W. Mendling, V. Loening-Baucke et al., "An adherent Gardnerella vaginalis biofilm persists on the vaginal epithelium after standard therapy with oral metronidazole," The American Journal of Obstetrics and Gynecology, vol. 198, no. 1, pp. 97.e1-97.e6, 2008.

[51] M. D. Harwich Jr., J. M. Alves, G. A. Buck et al., "Drawing the line between commensal and pathogenic Gardnerella vaginalis through genome analysis and virulence studies," $B M C$ Genomics, vol. 11, no. 1, article 375, 2010.

[52] Y. Turovskiy, K. Sutyak Noll, and M. L. Chikindas, “The aetiology of bacterial vaginosis," Journal of Applied Microbiology, vol. 110, no. 5, pp. 1105-1128, 2011.
[53] J. Twin, C. S. Bradshaw, S. M. Garland, C. K. Fairley, K. Fethers, and S. N. Tabrizi, "The potential of metatranscriptomics for identifying screening targets for bacterial vaginosi," PLoS ONE, vol. 8, no. 9, Article ID e76892, 2013. 


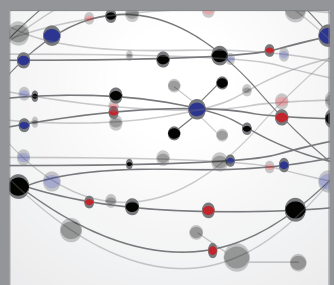

The Scientific World Journal
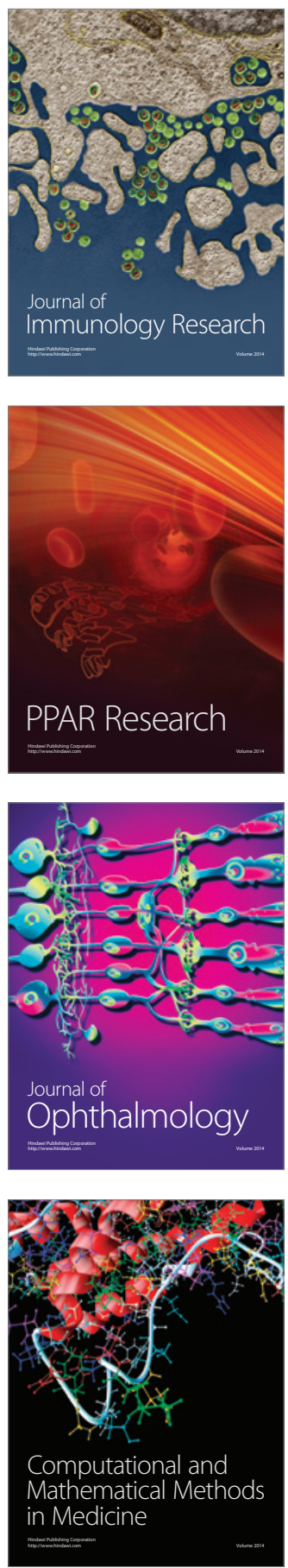

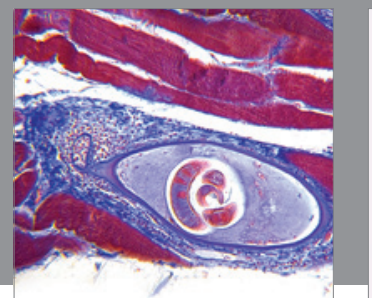

Gastroenterology

Research and Practice
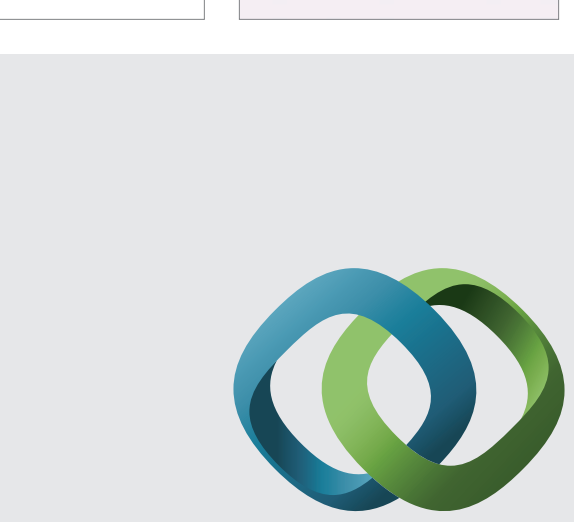

\section{Hindawi}

Submit your manuscripts at

http://www.hindawi.com
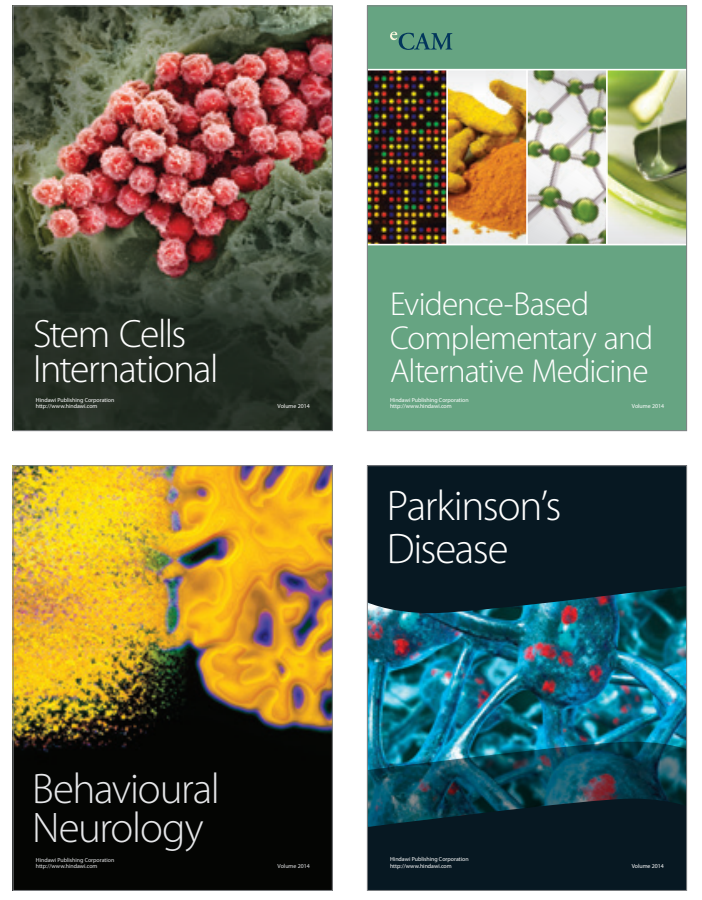
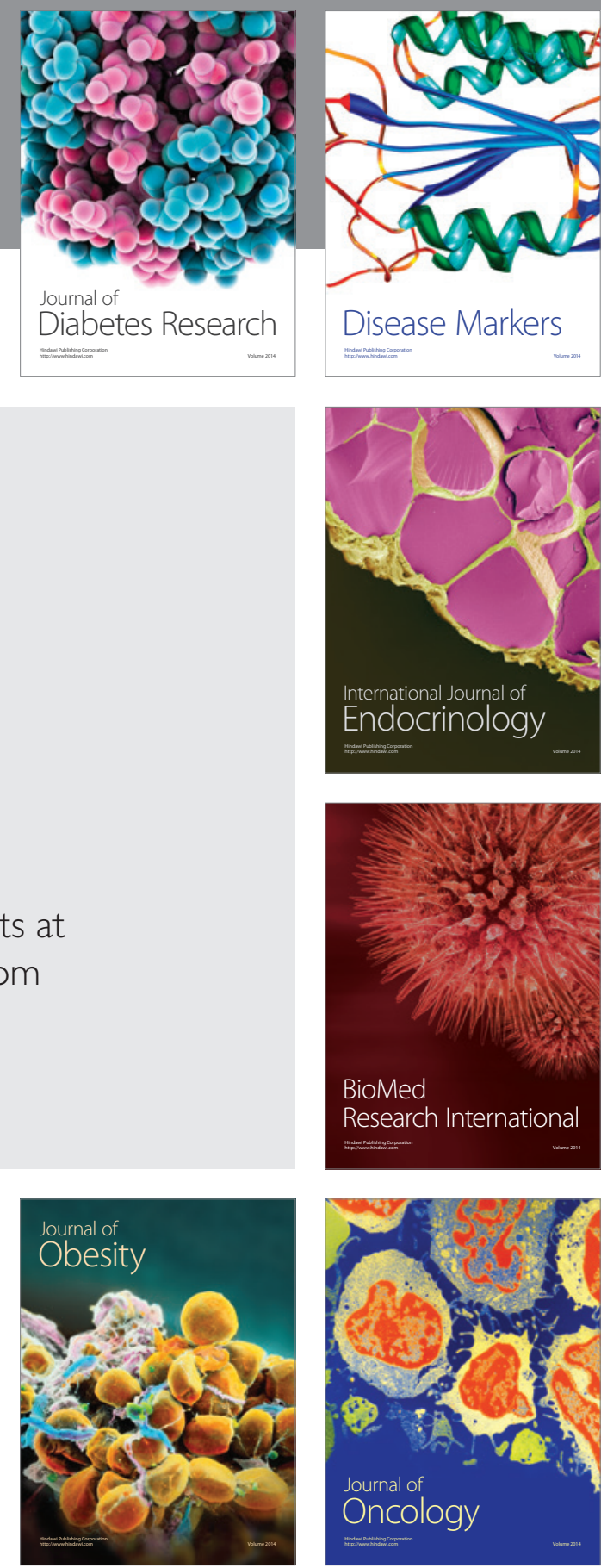

Disease Markers
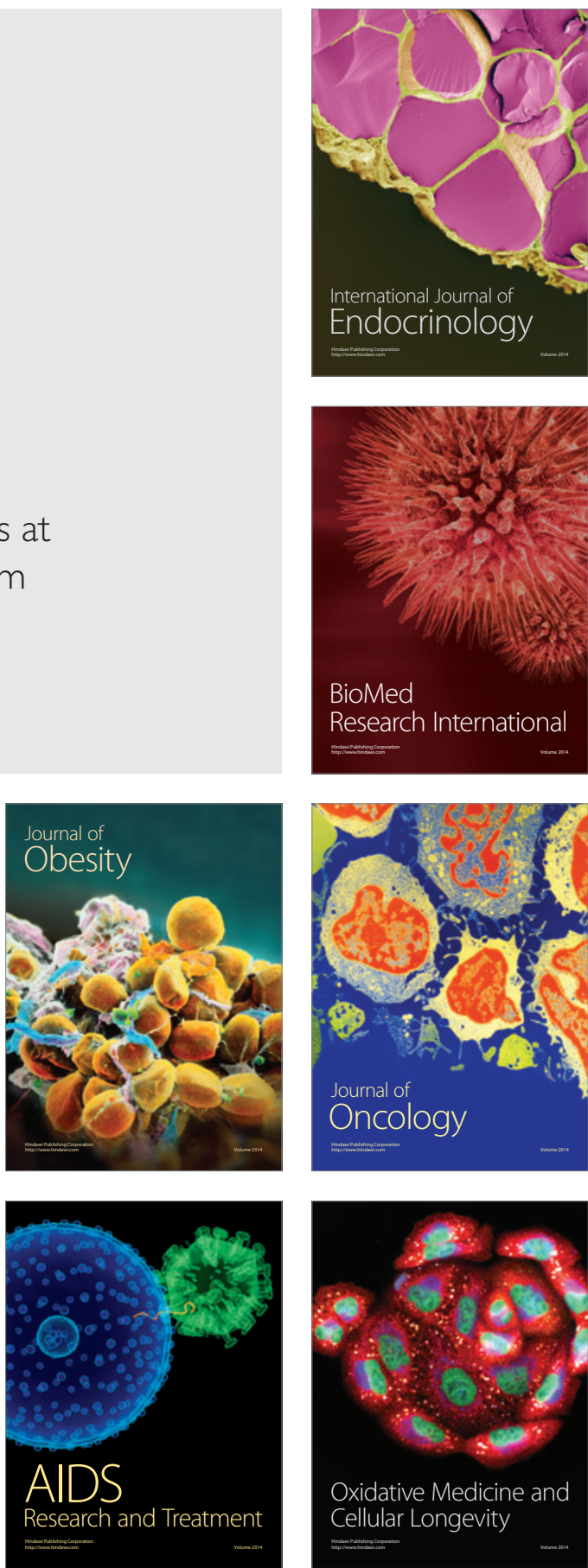